\title{
Decarburization and Oxygen Absorption of Molten Iron of Low Carbon Concentration with Blowing $\mathrm{Ar}-\mathrm{O}_{2}$ Mixture of Low Oxygen Pressure
}

\author{
Masamichi SANO, HAN Yetao, ${ }^{1)}$ Tadashi SAWADA ${ }^{2)}$ and Masakazu KATO ${ }^{3)}$ \\ School of Engineering, Nagoya University, Furo-cho, Chikusa-ku, Nagoya, Aichi-ken, 464-01 Japan. \\ 1) Formerly Graduate School, Nagoya University. Now at S-TEM, Ltd., Futano-cho, Mizuho-ku, Nagoya, Aichi-ken, 467 \\ Japan. $\quad 2$ ) Formerly Graduate School, Nagoya University. Now at Aichi Steel Works, Ltd., Wano-wari, Arao-cho, Tokai, \\ Aichi-ken, 476 Japan. $\quad 3$ ) Formerly Graduate School, Nagoya University. Now at Nippon Gaishi, Ltd., Maegata-cho, \\ Handa, Aichi-ken, 475 Japan.
}

\begin{abstract}
Kinetics of decarburization and oxygen absorption of molten iron of low carbon and oxygen concentrations has been studied. The decarburization and oxygen absorption experiments were performed by blowing $\mathrm{Ar}-\mathrm{O}_{2}$ mixture (oxygen partial pressure $1.0 \times 10^{-5}<P_{\mathrm{O}_{2}}(\mathrm{~atm})<5.5 \times 10^{-2}$ and gas-flow rate 1000 (and 1900 ) $\mathrm{Ncm}^{3} / \mathrm{min}$ ) onto the melt surface. The rates of decarburization and oxygen absorption increase with increasing oxygen partial pressure $P_{\mathrm{O}_{2}}>\sim 5 \times 10^{-3} \mathrm{~atm}$ ). At oxygen partial pressures of $P_{\mathrm{O}_{2}}<1.0 \times 10^{-4}$ atm, the oxygen concentration is kept almost constant. The total reaction rate of oxygen with the melt (=decarburization rate+oxygen absorption rate) is larger than the rate of oxygen absorption without decarburization and smaller than the rate calculated from a reaction model of oxygen diffusion in the gas phase. It is presumed that formation of oxide film on the melt surface has an influence on the decarburization and oxygen absorption rates. A mathematical model is proposed to explain the rates of decarburization and oxygen absorption.
\end{abstract}

KEY WORDS: kinetics; molten iron; $\mathrm{Ar}-\mathrm{O}_{2}$ blowing; decarburization; oxygen absorption; low oxygen concentration; low carbon concentration; low carbon steel.

\section{Introduction}

Lowering of carbon content of steel has large effects on improving toughness and weldability of the steel. With development of a continuous annealing process, in which rapid heating and annealing is necessary, production of ultra-low carbon steel is essential for obtaining superior non-aging property and formability.

There have many fundamental studies on decarburization of molten iron. Relatively earlier literature was reviewed by Gunji. ${ }^{1)}$ Later, Nomura and Mori, ${ }^{2,3)}$ Ghosh, ${ }^{4,5)}$ Sain and Belton, ${ }^{6,7)}$ Lee and Rao, ${ }^{8,9)}$ Harashima et $a l .^{10)}$ and many others have studied from various points of view.

Decarburization of molten iron of low carbon concentration with blowing oxidizing gas accompanies oxygen absorption and also formation of oxide film, ${ }^{11,12)}$ so that the reaction mechanism is complicated, and has not yet wholly been made clear.

This paper is concerned with kinetics of decarburization of molten iron of low carbon and oxygen concentrations with blowing $\mathrm{Ar}-\mathrm{O}_{2}$ mixture of low oxygen pressure. In addition, oxygen absorption of molten iron is also studied with blowing the mixture. The total reaction rates of oxygen (= oxygen absorption rate + decarburization rate) are compared between oxygen absorption and simultaneous oxygen absorption and decarburization, and the reaction mechanism is discussed

\section{Experimental}

\subsection{Experimental Apparatus}

Figure 1 shows a schematic diagram of the experimental apparatus. A high frequency induction furnace was used to melt electrolytic iron in a magnesia crucible of $38 \mathrm{~mm}$ in I.D. and $100 \mathrm{~mm}$ in height. Ar- $\mathrm{O}_{2}$ mixture was blown onto the melt surface through an

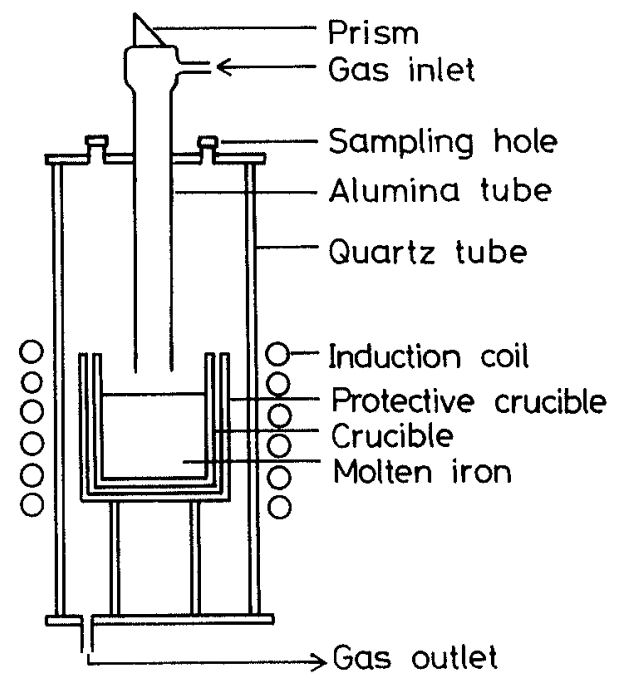

Fig. 1. Experimental apparatus. 
alumina lance of $10 \mathrm{~mm}$ in I.D. The distance between the lance tip and the melt surface was $10 \mathrm{~mm}$. The flow rates of $\mathrm{Ar}$ and $\mathrm{O}_{2}$ were measured with a mass flow meter and a capillary flow meter. The partial oxygen pressure of the mixture, $P_{\mathrm{O}_{2}}$, was measured continuously with an oxygen sensor in the gas supply train. Control of $P_{\mathrm{O}_{2}}$ higher than $5.0 \times 10^{-3}$ atm was made by mixing $\mathrm{Ar}$ and $\mathrm{O}_{2}$ of fixed flow rates, and $P_{\mathrm{O}_{2}}$ lower than $5.0 \times 10^{-3} \mathrm{~atm}$ by passing Ar through a heated packed bed of $\mathrm{Cu}_{2} \mathrm{O}$ and $\mathrm{CuO}$ pins. In the latter case, $P_{\mathrm{O}_{2}}$ was in good agreement with the equilibrium value of the following reaction.

$$
\mathrm{Cu}_{2} \mathrm{O}+\frac{1}{2} \mathrm{O}_{2}=2 \mathrm{CuO}
$$

\subsection{Experimental Procedure}

After melting the iron in the crucible, mixture of $\mathrm{Ar}$ and $\mathrm{H}_{2}$ was blown onto the melt surface to deoxidize the melt and the temperature was maintained as $1580^{\circ} \mathrm{C}$. In the case of a decarburization experiment, an appropriate amount of carbon was added to control the initial carbon content of the melt. Then, $\mathrm{Ar}-\mathrm{O}_{2}$ mixture was blown onto the surface to initiate the kinetic experiment. Metal samples were taken at appropriate time intervals and analyzed to obtain oxygen and carbon concentrations of the metal by a coulometric titration method.

The mass of the melt was $400 \mathrm{~g}$. The initial carbon and oxygen concentrations were $0-240$ and $20-50 \mathrm{ppm}$. The oxygen partial pressure of the $\mathrm{Ar}-\mathrm{O}_{2}$ mixture, $P_{\mathrm{O}_{2}}$, was varied in the range of $1.0 \times 10^{-5}<P_{\mathrm{O}_{2}}$ (atm) $<5.5 \times$ $10^{-2}$. The gas flow rate was mainly $1000 \mathrm{Ncm}^{3} / \mathrm{min}$, and in some experiments $1900 \mathrm{Ncm}^{3} / \mathrm{min}$. The experimental temperature was $1580^{\circ} \mathrm{C}$.

\section{Experimental Results}

\subsection{Decarburization Reaction}

Figure 2 shows changes in carbon and oxygen concentrations of molten iron with time obtained by blowing $\mathrm{Ar}-\mathrm{O}_{2}$ mixture of $P_{\mathrm{O}_{2}}=4.9 \times 10^{-3} \mathrm{~atm}$. At first, the carbon concentration decreases linearly with time, and the increase in the oxygen concentration is only a little. The decarburization rate is larger for higher gas flow rate. However, it becomes smaller with decreasing

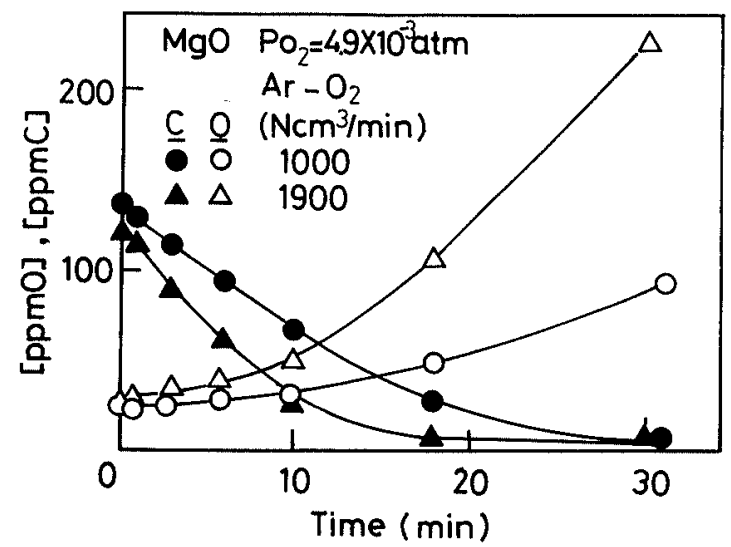

Fig. 2. Effect of gas-flow rate on decarburization and oxygen absorption. carbon concentration, and rapid oxygen absorption takes place.

Changes in carbon and oxygen concentrations with time for various oxygen partial pressures, $P_{\mathrm{O}_{2}}$, are shown in Fig. 3. At higher $P_{\mathrm{O}_{2}}$, the decarburization rate is larger, but the oxygen concentration tends to increase from the initial stage. The increase in the oxygen concentration is notable with lowering carbon concentration. At a low $P_{\mathrm{O}_{2}}$ of $1.0 \times 10^{-4}$ atm, the decarburization reaction proceeds, but the reaction rate is considerably low. It is to be noted that in this case the oxygen concentration is kept almost constant.

The relation between the decarburization rate and the carbon concentration is shown in Fig. 4. In the range of carbon concentration larger than $50 \mathrm{ppm}$, the rate is larger at higher $P_{\mathrm{O}_{2}}$, and does not change much with the carbon concentration. However, when the carbon concentration is lower than $50 \mathrm{ppm}$, the rate decreases rapidly with decreasing carbon concentration, and its dependence on $P_{\mathrm{O}_{2}}$ becomes smaller.

\subsection{Oxygen Absorption Reaction}

Figure 5 shows changes in oxygen concentration of molten iron with time for $P_{\mathrm{O}_{2}}>1.0 \times 10^{-2} \mathrm{~atm}$. It is seen that the oxygen concentration increases linearly with time, and the oxygen absorption rate increases with increasing $P_{\mathrm{O}_{2}}$. In the case of $P_{\mathrm{O}_{2}}=5.5 \times 10^{-2}$ atm, after

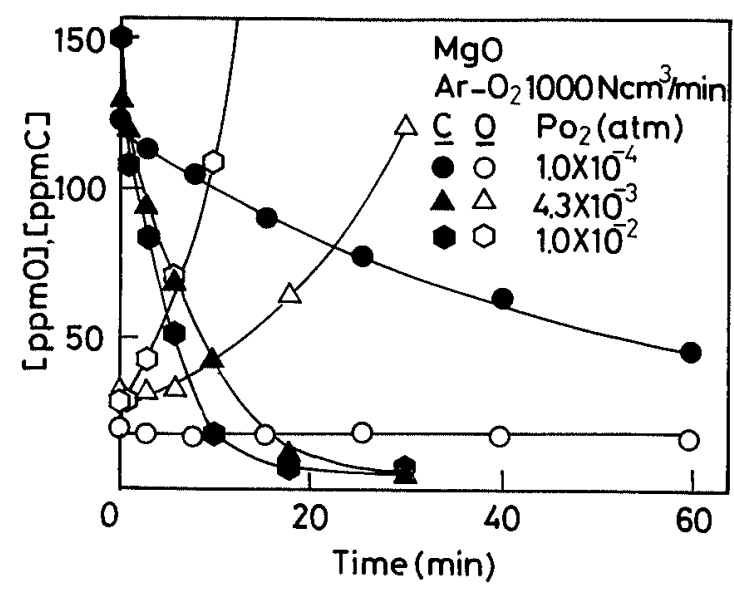

Fig. 3. Effect of oxygen partial pressure on decarburization and oxygen absorption.

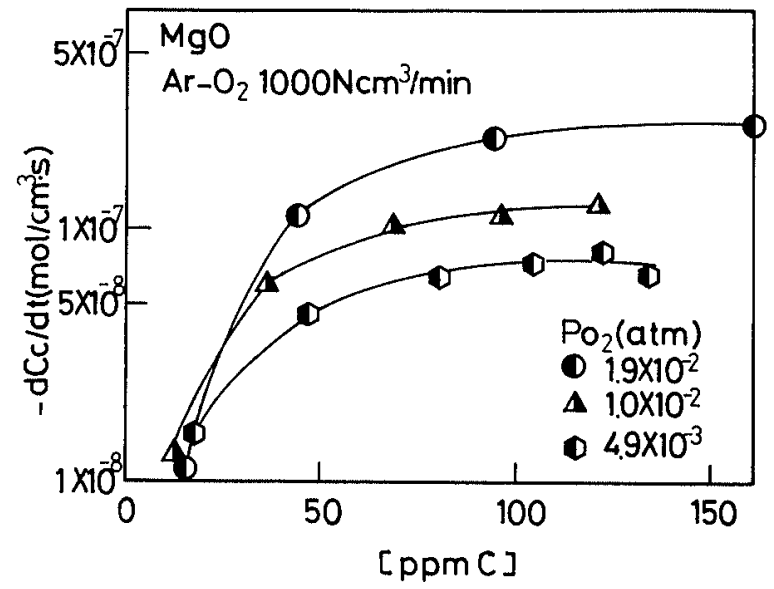

Fig. 4. Relation between decarburization rate and carbon concentration. 


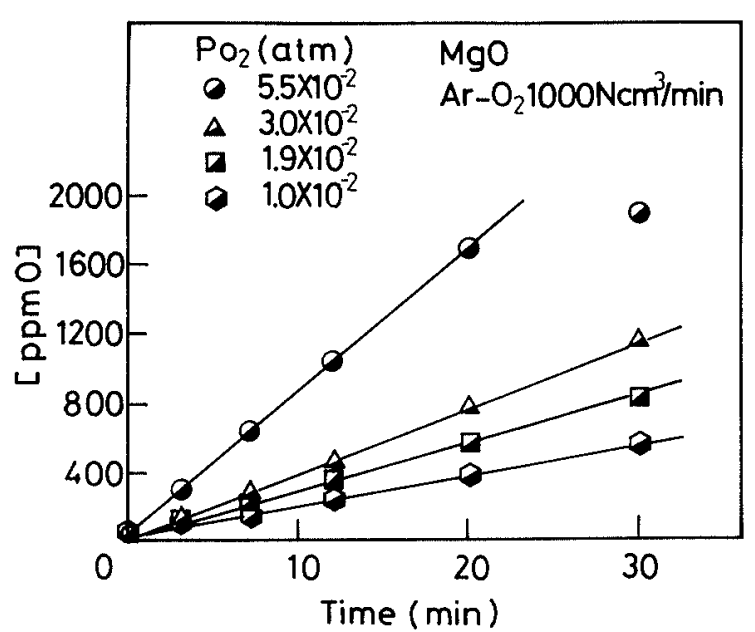

Fig. 5. Effect of oxygen partial pressure on oxygen absorption.

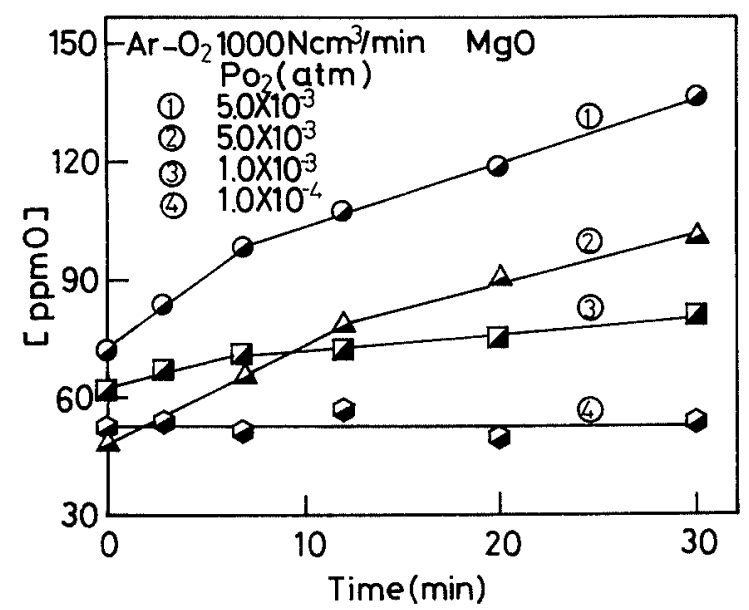

Fig. 6. Effect of low oxygen partial pressure on oxygen absorption.

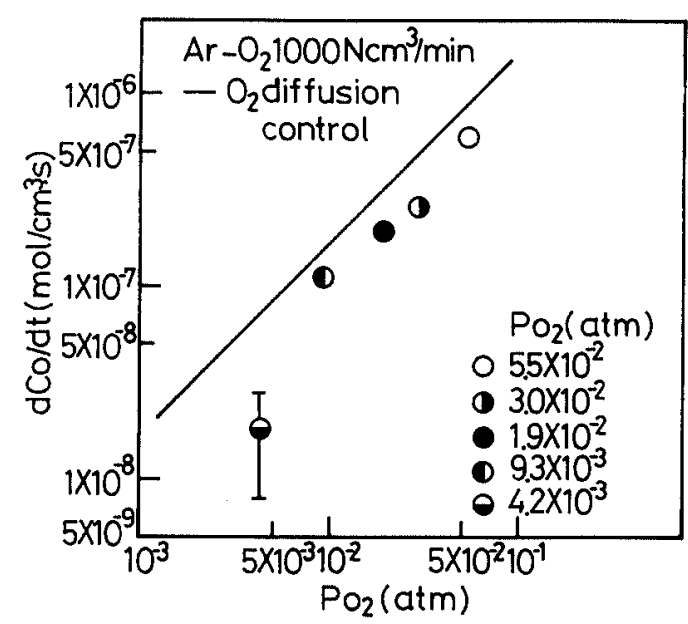

Fig. 7. Relation between oxygen absorption rate and oxygen partial pressure.

20 min the oxygen concentration becomes very high, and the absorption rate becomes very low.

In Fig. 6, the experimental results are plotted for relatively low $P_{\mathrm{O}_{2}}\left(<5 \times 10^{-3}\right.$ atm). Also in this $P_{\mathrm{O}_{2}}$ range, the oxygen absorption rate increases with increasing $P_{\mathrm{O}_{2}}$. Except the case of $P_{\mathrm{O}_{2}}=1.0 \times 10^{-4} \mathrm{~atm}$, the absorption rate slows down at about $10 \mathrm{~min}$. In the case (4), the oxygen concentration remains almost constant.

Figure 7 shows the relation between the oxygen absorption rate and $P_{\mathrm{O}_{2}}$. The absorption rate for $P_{\mathrm{O}_{2}}>1.0 \times 10^{-2} \mathrm{~atm}$ increases in proportion to the increase in $P_{\mathrm{O}_{2}}$. At $P_{\mathrm{O}_{2}}=4.2 \times 10^{-3} \mathrm{~atm}$, however, the rate is fairly small.

\section{Discussion}

\subsection{Rate Determining Mechanism of Decarburization of Molten Iron in Low Carbon Concentration Range}

The decarburization rate of molten iron of low carbon concentration is dependent on the oxygen partial pressure, flow rate of the blowing gas and the carbon concentration of the melt. Hence, the possible rate determining steps are gas-phase oxygen transfer, interfacial chemical reaction, liquid-phase carbon transfer and gas-phase carbon monoxide transfer.

Firstly, the rate is assumed to be controlled only by the gas-phase oxygen transfer or by the liquid-phase carbon transfer. Then, the decarburization rate is given by Eq. (2) or (3).

$$
\begin{aligned}
& -\frac{d C_{\mathrm{C}}}{d t}=2\left(\frac{k_{G, \mathrm{O}_{2}}}{R T}\right)\left(\frac{A}{V}\right)\left(P_{\mathrm{O}_{2}}-P_{\mathrm{O}_{2}, i}\right) \\
& -\frac{d C_{\mathrm{C}}}{d t}=k_{L, \mathrm{C}}\left(\frac{A}{V}\right)\left([\% \mathrm{C}]-\left[\% \mathrm{C}_{i}\right)\left(\frac{\rho_{L}}{100 M_{\mathrm{C}}}\right)\right. \text {. }
\end{aligned}
$$

where $C$ is the molar concentration of solute in molten iron $\left(\mathrm{mol} / \mathrm{cm}^{3}\right), t$ is the time (s), $k$ is the mass transfer coefficient $(\mathrm{cm} / \mathrm{s}), R$ is the gas constant $\left(\mathrm{cm}^{3} \cdot \mathrm{atm} / \mathrm{K}\right.$. $\mathrm{mol}), T$ is the temperature (K), $A$ is the surface area of molten iron $\left(\mathrm{cm}^{2}\right), V$ is the metal volume $\left(\mathrm{cm}^{3}\right), P$ is the pressure (atm), $\rho$ is the density of molten metal, $M$ is the molecular mass $(\mathrm{g} / \mathrm{mol})$, and the subscript $\mathrm{C}$ is carbon, $\mathrm{O}_{2}$ is oxygen, $G$ is the gas, $L$ is the liquid, and $i$ is the reaction interface. In the calculation, both $P_{\mathrm{O}_{2}, i}$ and $[\% \mathrm{C}]_{i}$ are taken as zero, and the gas-phase mass transfer coefficient is obtained by applying the correlating equation of Kikuchi et al. ${ }^{13)}$ The liquid-phase mass transfer is estimated as follows. The authors studied nitrogen absorption of molten iron by using the same high frequency induction furnace and analyzed the experimental data with a mixed control model ${ }^{14)}$ to obtain the liquid-phase transfer coefficient of nitrogen, $k_{L, \mathrm{~N}}$. And $k_{L, \mathrm{C}}$ was estimated from $k_{L, \mathrm{~N}}$ by multiplying the square root of the ratio of liquid-phase diffusivity of carbon to that of nitrogen.

The decarburization rate is calculated from Eqs. (2) and (3) and compared with the experimental results in Fig. 8. At $P_{\mathrm{O}_{2}}=1.9 \times 10^{-2}$ and $4.9 \times 10^{-3}$ atm, the decarburization rate obtained experimentally at the initial stage of the experiments (or in the range of relatively higher carbon concentration) is close to that calculated from Eq. (2) and smaller than that from Eq. (3). As the carbon concentration decreases, however, even the calculated rate from Eq. (2) becomes much larger than the experimental one. It is to be noted that the decarburization rate at $P_{\mathrm{O}_{2}}=1.0 \times 10^{-4} \mathrm{~atm}$ is about 10 times larger than that calculated from Eq. (2), while the oxygen concentration was kept constant as shown in Fig. 


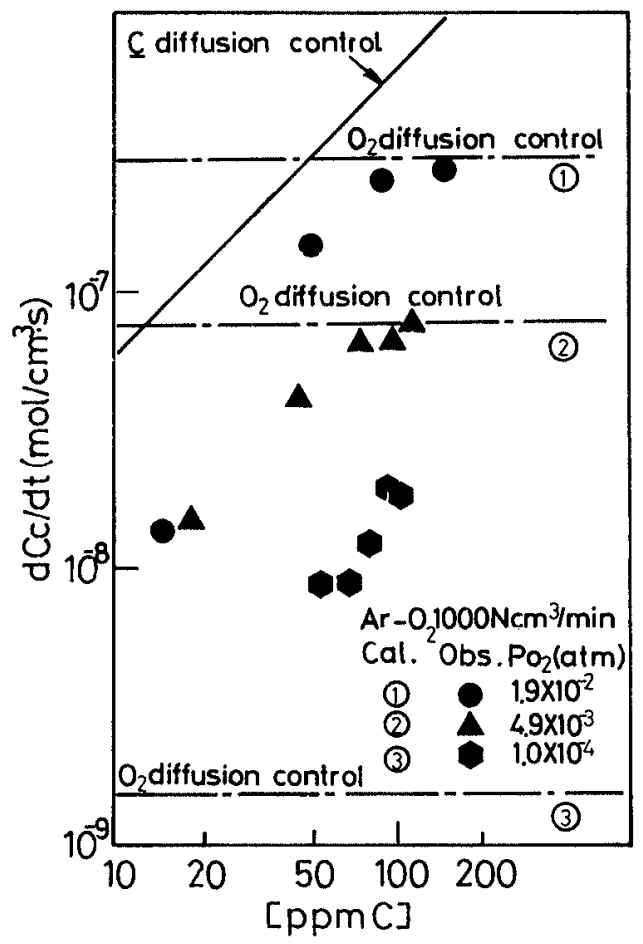

Fig. 8. Comparison of decarburization rate between experiment and calculation from diffusion control model.

3. This fact clearly indicates that the decarburization proceeded through the reaction of carbon in the metal with the refractory oxide $(\mathrm{MgO})$.

It is considered from Fig. 8 that at $P_{\mathrm{O}_{2}}>\sim 5 \times 10^{-3}$ atm and in the range of lower carbon concentration there exist rate determining steps other than the gas-phase mass transfer of oxygen and the liquid-phase mass transfer of carbon.

\subsection{Rate Determining Mechanism of Oxygen Absorp- tion into Molten Iron with Blowing $\mathrm{Ar}-\mathrm{O}_{2}$ Mixture of Low Oxygen Partial Pressure}

Previous studies have shown that in the case of oxygen absorption into molten iron with blowing pure oxygen, after an oxide film is formed the rate decreases largely and is proportional to $P_{\mathrm{O}_{2}}^{1 / 2} \cdot{ }^{15,16)}$ When an $\mathrm{Ar}-\mathrm{O}_{2}$ mixture of $P_{\mathrm{O}_{2}}<5.7 \times 10^{-2} \mathrm{~atm}$ is blown onto the melt surface, the absorption rate is assumed to be controlled by the gas-phase mass transfer of oxygen. ${ }^{17}$ )

On the assumption of gas-phase mass trasfer control, the oxygen absorption rate is calculated from Eq. (4).

$$
\frac{d C_{\mathrm{O}}}{d t}=2\left(\frac{k_{\mathrm{G}, \mathrm{O}_{2}}}{R T}\right)\left(\frac{A}{V}\right)\left(P_{\mathrm{O}_{2}}-P_{\mathrm{O}_{2}, i}\right)
$$

where $C_{\mathrm{o}}$ is the molar concentration of oxygen atom in molten iron $\left(\mathrm{mol} / \mathrm{cm}^{3}\right)$. Here, $P_{\mathrm{O}_{2}, i}$ can be taken as zero in the calculation.

The calculated result is shown by a solid line in Fig. 7. As clearly seen from the figure, the experimental absorption rate is lower than the calculated one. Accordingly, the absorption rate is not solely controlled by the gas-phase mass transfer.

Visual observation on the melt surface showed that at $P_{\mathrm{O}_{2}}>1.0 \times 10^{-2} \mathrm{~atm}$, small oxide particles moved around after 1-3 min from the start of experiment, and then the

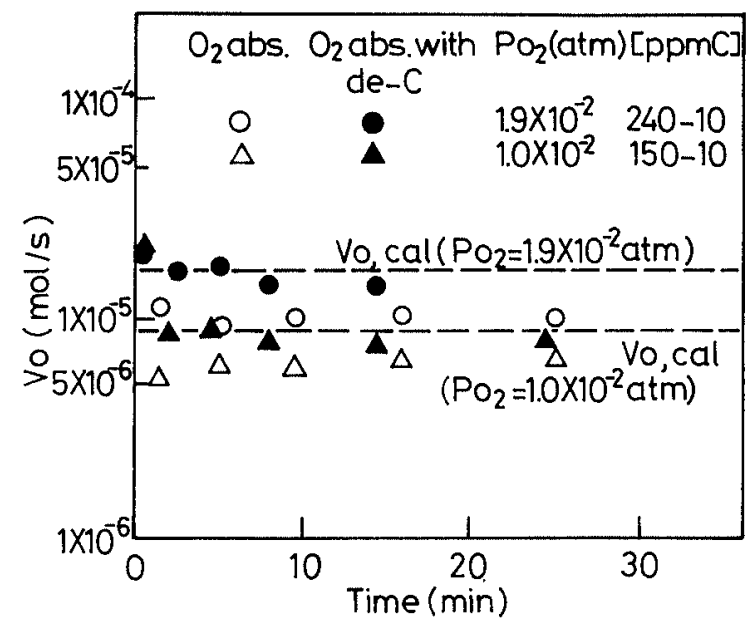

Fig. 9. Comparison between total reaction rates of oxygen with melt with and without decarburization.

surface was covered by the oxide film. When $P_{\mathrm{O}_{2}}$ is lower than $5.0 \times 10^{-3} \mathrm{~atm}$, no oxide film was visually observed.

As shown in Fig. 6, at first the absorption rate was large, but tended to decrease after about $10 \mathrm{~min}$. It is presumed that an oxide film, which was not visually observable, might have formed on the surface.

The above considerations suggest that when the argon-oxygen mixture is blown onto the iron melt, a thin oxide film may produce additional rate determining steps, such as mass transfer through the film, absorption and chemical reaction at the interface.

\subsection{Comparison of Total Reaction Rates of Oxygen with and without Decarburization}

When $\mathrm{Ar}-\mathrm{O}_{2}$ mixture is blown to decarburize the iron melt, oxygen reacts with carbon in the melt and is absorbed into it at the same time. Hence, the surface condition, such as formation of an oxide film, may differ between oxygen absorptions with and without decarburization. To investigate the difference, the total reaction rate of oxygen, $V_{\mathrm{o}}(\mathrm{mol} / \mathrm{s})$, is calculated from the experimental result. Here, $V_{0}$ is defined as the sum of decarburization and oxygen absorption rates.

In Fig. 9, changes in $V_{O}$ with time are shown for decarburization and oxygen absorption experiments at oxygen partial pressures of $1.9 \times 10^{-2}$ and $1.0 \times 10^{-2}$ $\mathrm{atm}$. The dashed line is the calculated reaction rate of oxygen, $V_{O \text {, cal }}$, using Eq. (4). Initially, $V_{O}$ with decarburization is close to the calculated value, but tends to decrease gradually with time, while $V_{\mathrm{O}}$ without decarburization is fairly small and does not change with time. Difference in $V_{\mathrm{o}}$ with and without decarburization shows a tendency to diminish with time.

The change in the total reaction rate of oxygen with time shown in Fig. 9 can be explained as follows. In the case of oxygen absorption with blowing $\mathrm{Ar}-\mathrm{O}_{2}$ mixture of $P_{\mathrm{O}_{2}} \geq 1.0 \times 10^{-2} \mathrm{~atm}$, an oxide film on the melt surface is formed at an early stage, and the absorption reaction proceeds under a nearly steady state condition. On the other hand, when the decarburization reaction takes place, it consumes the oxygen supplied to the melt surface, so that formation of the oxide film is delayed. As the carbon concentration of the melt decreases, the 


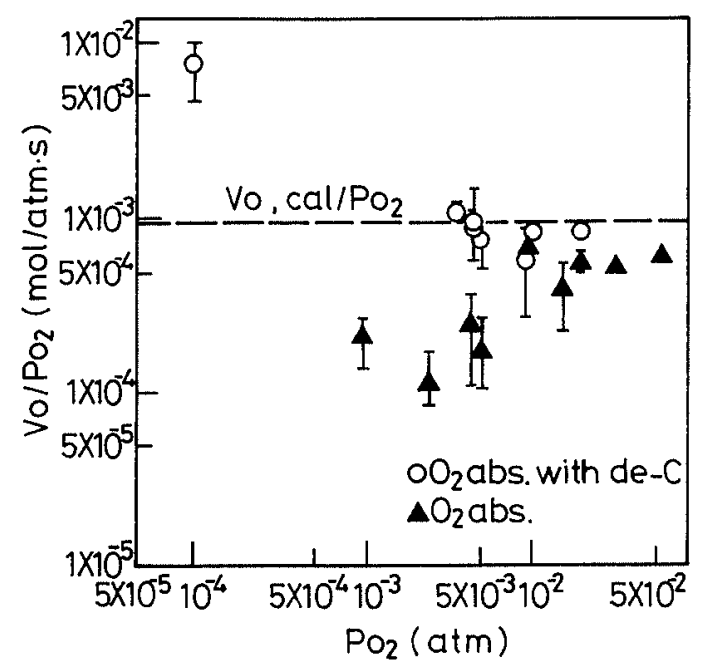

Fig. 10. Relation between $V_{\mathrm{O}} / P_{\mathrm{O}_{2}}$ and $P_{\mathrm{O}_{2}}$.

decarburization rate becomes smaller, and the oxide film is formed. This makes the total reaction rate of oxygen approach to that for the oxygen absorption without decarburization.

Figure 10 shows the total reaction rate of oxygen divided by the oxygen partial pressure, $V_{\mathrm{O}} / P_{\mathrm{O}_{2}}$, plotted against $P_{\mathrm{O}_{2}}$. It is seen that $V_{\mathrm{O}} / P_{\mathrm{O}_{2}}$ for simultaneous decarburization and oxygen absorption reactions increases with decreasing $P_{\mathrm{O}_{2}}$, while that for oxygen absorption reaction has an opposite tendency. The increase in $V_{\mathrm{o}} / P_{\mathrm{O}_{2}}$ with decreasing $P_{\mathrm{O}_{2}}$ in the former case is attributable to the decarburization by a crucible reaction $(\underline{\mathrm{C}}+\mathrm{MgO}=\mathrm{CO}+\mathrm{Mg})$ in the very low oxygen partial pressure range. In the latter case, a gas-phase reaction of oxygen with evaporated iron and/or consumption of oxygen for oxide formation is considered to decrease $V_{\mathrm{O}} / P_{\mathrm{O}_{2}}$.

\subsection{Reaction Model}

In the present reaction model, the rate processes in the oxide film, such as oxygen transfer through the film and chemical reaction at the interface are taken into account, in addition to the gas- and liquid-phase mass transfers.

\subsubsection{Oxygen Absorption Model}

Since the detailed mechanism of the rate phenomena in the oxide film is not known, the rate is assumed to be proportional to the difference in oxygen partial pressures at the gas-oxide film and at the oxide film-iron interfaces.

The flux for each rate determining step is expressed as follows.

$$
\begin{aligned}
J_{\mathrm{O}_{2}} & =\left(\frac{k_{\mathrm{G}, \mathrm{O}_{2}}}{R T}\right)\left(P_{\mathrm{O}_{2}}-P_{\mathrm{O}_{2}, \mathrm{O} i}\right) \\
& =k_{m, \mathrm{O}_{2}}\left(P_{\mathrm{O}_{2}, \mathrm{O} i}-P_{\mathrm{O}_{2}, m i}\right) \\
J_{\mathrm{O}} & =k_{L, \mathrm{O}}\left(C_{\mathrm{O}, m i}-C_{\mathrm{O}}\right) \\
J_{\mathrm{O}} & =2 J_{\mathrm{O}_{2}}
\end{aligned}
$$

where $J_{\mathrm{O}_{2}}$ is the molar flux of gaseous oxygen $\left(\mathrm{mol} / \mathrm{cm}^{2} \cdot \mathrm{s}\right), J_{\mathrm{O}}$ is the molar flux of oxygen atom in the metal $\left(\mathrm{mol} / \mathrm{cm}^{2} \cdot \mathrm{s}\right), k_{m}$ is the apparent rate constant for the rate processes in the oxide film $\left(\mathrm{mol} / \mathrm{cm}^{2} \cdot \mathrm{s} \cdot \mathrm{atm}\right)$, the subsript $\mathrm{O}_{2}$ is the gaseous oxygen, $\mathrm{O}$ is the oxygen in the metal, $\mathrm{O} i$ is the gas-oxide film interface and $m i$ is the oxide film-iron interface.

The values of $k_{G, O_{2}}$ and $k_{L, O}$ can be estimated from available data. Therefore, if $k_{m, O_{2}}$ is given, the concentration of each component at the interfaces can be determined. In the calculation, $P_{\mathrm{O}_{2}, m i}$ can be taken as zero to obtain $J_{\mathrm{O}_{2}}$.

Being unable to calculate $J_{\mathrm{O}}$ from Eq. (7), we calculate it from Eq. (8) using the calculated $J_{\mathrm{O}_{2}}$. The change in the oxygen concentration of molten iron with time can be obtained by Eq. (9).

$$
\frac{d[\% \mathrm{O}]}{d t}=J_{\mathrm{O}}\left(\frac{A}{V}\right)\left(100 \frac{M_{\mathrm{O}}}{\rho_{L}}\right)
$$

where $M_{\mathrm{O}}$ is the atomic mass of oxygen $(\mathrm{g} / \mathrm{mol})$.

\subsubsection{Decarburization Model}

In the case of decarburization of molten iron of very low carbon concentration with blowing $\mathrm{Ar}-\mathrm{O}_{2}$ mixture, the oxygen absorption reaction occurs simultaneously. The molar fluxes of the reacting species are written as

$$
\begin{aligned}
& J_{\mathrm{O}_{2}}=\left(\frac{k_{G, \mathrm{O}_{2}}}{R T}\right)\left(P_{\mathrm{O}_{2}}-P_{\mathrm{O}_{2}, \mathrm{O} i}\right) \\
& =k_{m, \mathrm{O}_{2}}\left(P_{\mathrm{O}_{2}, \mathrm{Oi}}-P_{\mathrm{O}_{2}, m i}\right) \\
& J_{\mathrm{O}}=k_{L, \mathrm{O}}\left(C_{\mathrm{O}, m i}-C_{\mathrm{O}}\right) \\
& J_{\mathrm{C}}=k_{L, \mathrm{C}}\left(C_{\mathrm{C}}-C_{\mathrm{C}, m i}\right) \\
& =k_{r}\left(C_{\mathrm{C}, m i} \cdot C_{\mathrm{O}, m i}-\frac{P_{\mathrm{CO}, m i}}{m_{\mathrm{CO}}}\right) \\
& =k_{m, \mathrm{CO}}\left(P_{\mathrm{CO}, m i}-P_{\mathrm{CO}, \mathrm{O} i}\right) \\
& =k_{r}^{\prime}\left(C_{\mathrm{C}, m i} \cdot C_{\mathrm{O}, m i}-\frac{P_{\mathrm{CO}, \mathrm{O} i}}{m_{\mathrm{CO}}}\right) \\
& =\left(\frac{k_{\mathrm{G}, \mathrm{CO}}}{E T}\right)\left(P_{\mathrm{CO}, \mathrm{O} i}-P_{\mathrm{CO}}\right) \\
& J_{\mathrm{O}}=2 J_{\mathrm{O}_{2}}-J_{\mathrm{C}}
\end{aligned}
$$

where $k_{r}$ is the reaction rate constant $\left(\mathrm{cm}^{4} / \mathrm{mol} \cdot \mathrm{s}\right), m_{\mathrm{CO}}$ is the apparent equilibrium constant $\left(\mathrm{cm}^{6} \cdot \mathrm{atm} / \mathrm{mol}^{2}\right)$, and the subscript $\mathrm{CO}$ is the $\mathrm{CO}$ gas. Since both the rate constants $k_{r}$ in Eq. (14) and $k_{m, \text { Co }}$ in Eq. (15) are unknown, we cannot determine the values individually. Therefore, an overall rate constant, $k_{r}^{\prime}$ in Eq. (16) is defined to evaluate the rate processes in the oxide film. In the calculation, $P_{\mathrm{O}_{2}, m i}$ can be taken as zero.

The change in oxygen concentration of molten iron with time can be obtained by Eq. (9) and that in carbon concentration by Eq. (19),

$$
-\frac{d[\% \mathrm{C}]}{d t}=J_{\mathrm{C}}\left(\frac{A}{V}\right)\left(100 \frac{M_{\mathrm{C}}}{\rho_{L}}\right)
$$

where $M_{\mathrm{C}}$ is the atomic mass of carbon $(\mathrm{g} / \mathrm{mol})$.

\subsection{Comparison of Calculated Result with Experimental One}

In Fig. 11, the calculated oxygen concentration change with time for the oxygen absorption at $P_{\mathrm{O}_{2}} \geq 1.0 \times 10^{-2}$ 


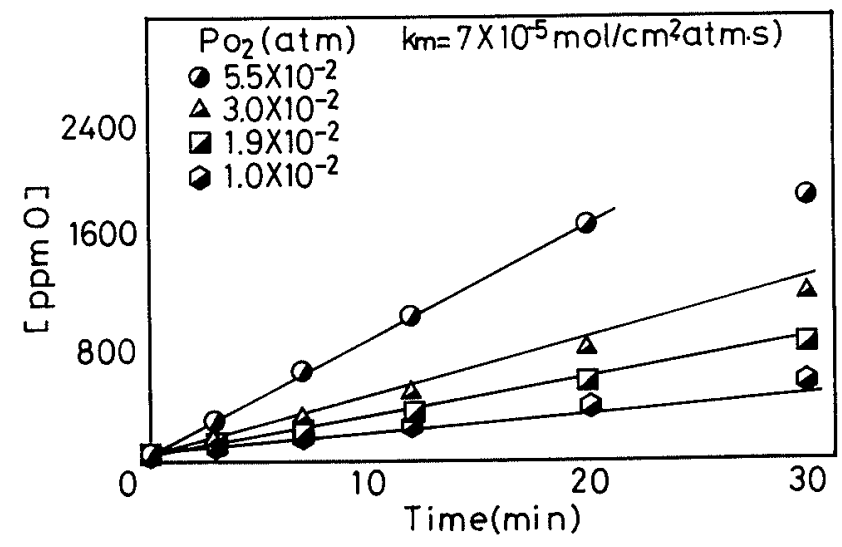

Fig. 11. Comparison between experiment and calculation for oxygen absorption.

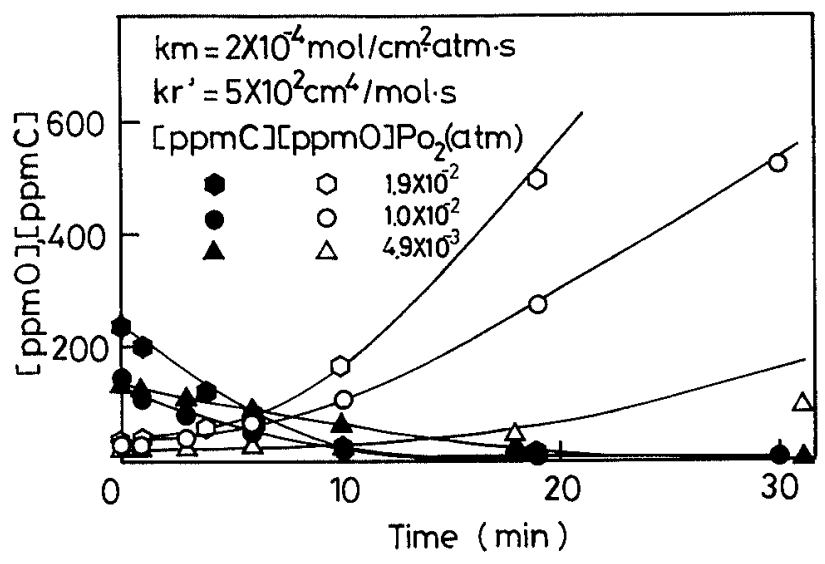

Fig. 12. Comparison between experiment and calculation for decarburization and oxygen absorption.

atm is compared with the experimental one. Here, $k_{m, \mathrm{o}_{2}}$ is taken as $7 \times 10^{-5} \mathrm{~mol} / \mathrm{cm}^{2} \cdot \mathrm{atm} \cdot \mathrm{s}$, which is determined with a trial and error method. As seen in Fig. 11, the calculated and experimental results are in good agreement, so that the present reaction model can explain the rate of oxygen absorption. Since the rate of formation and the thickness of the oxide film may change in the course of the absorption experiment and depend on the oxygen partial pressure of the blowing gas mixture, $P_{\mathrm{O}_{2}}$, $k_{m, \mathrm{O}_{2}}$ is expected to vary with $P_{\mathrm{O}_{2}}$. However, the present experimental results can be explained by using a constant value of $k_{m, \mathrm{O}_{2}}$ in the range of $1.0 \times 10^{-2}<P_{\mathrm{O}_{2}}$ (atm) $<5.5 \times 10^{-2}$. As stated earlier, in the range of $P_{\mathrm{O}_{2}} \leq 5.0 \times 10^{-3} \mathrm{~atm}$, consumption of oxygen by the gas-phase reaction of oxygen with the evaporated iron and/or by the formation of the oxide film may not be negligible, and hence comparison of the calculated result with the experimental one is not made.

As for the decarburization reaction, the changes in carbon and oxygen concentrations with time are claculated and shown in Fig. 12 to compare with the experimental ones. Good agreement is seen between the two. The rate constants used in the calculation are shown in the figure. The value of $k_{m, O_{2}}$ for simultaneous decarburization and oxygen absorption is three times larger than that for oxygen absorption. It is thought that when the decarburization reaction occurs, the formation of oxide film is suppressed, and hence $k_{m, \mathrm{O}_{2}}$ becomes larger.

Although presumably $k_{m, \mathrm{O}_{2}}$ should change with $P_{\mathrm{O}_{2}}$ of the blowing gas and also during each experimental run, it is fixed at a constant value. The agreement between the calculated and the experimental results in Figs. 11 and 12 may be due to that the present experimental conditions were not changed widely.

In the range of $P_{\mathrm{O}_{2}} \leq 5.0 \times 10^{-3}$ atm the decarburization and oxygen absorption reactions are affected by the reaction of oxygen with the evaporated iron and the reaction of carbon with the crucible oxide. Consequently, the mechanism of the decarburization reaction becomes very complex. The decarburization of molten iron according to the reaction of carbon with refractory oxides will be investigated in details in a next paper.

\section{Conclusion}

Experiments of decarburization and oxygen absorption of molten iron in the ranges of low carbon and oxygen concentrations have been made by blowing Ar- $\mathrm{O}_{2}$ mixture of low oxygen partial pressure. Mechanisms of decarburization and oxygen absorption reactions are discussed on the basis of the experimental results. From this, reaction models are developed to explain the reaction rates quantitatively.

The results are summarized as follows.

(1) In the range of oxygen partial pressure $P_{\mathrm{O}_{2}} \geq$ $\sim 5 \times 10^{-3} \mathrm{~atm}$, the decarburization rate increases with increasing $P_{\mathrm{O}_{2}}$, and the oxygen absorption reaction occurs simultaneously and the oxygen concentration increases. Even at $P_{\mathrm{O}_{2}} \leq 1.0 \times 10^{-4}$ atm, the decarburization does proceed, while the oxygen concentration remains almost constant.

(2) The oxygen absorption rate increases with increasing $P_{\mathrm{O}_{2}}$ in the range of $1.0 \times 10^{-2} \leq P_{\mathrm{O}_{2}}$ (atm) $\leq 5.5 \times 10^{-2}$, but the rate is almost zero for $P_{\mathrm{O}_{2}} \leq 1.0 \times 10^{-4}$ atm.

(3) In the case of blowing $\mathrm{Ar}-\mathrm{O}_{2}$ mixture of low $P_{\mathrm{O}_{2}}\left(P_{\mathrm{O}_{2}} \leq 10^{-4} \mathrm{~atm}\right)$, the decarburization reaction proceeds through a reaction of carbon in molten iron with refractory oxide.

(4) The total oxygen reaction rate (=decarburization rate + oxygen absorption rate) for simultaneous decarburization and oxygen absorption is larger than that for oxygen absorption.

(5) The decarburization and oxygen absorption models considering the rate processes in the oxide film on the surface of molten iron can explain the experimental results quantitatively.

\section{REFERENCES}

1) K. Gunji: Trans. Iron Steel Inst. Jpn., 10 (1970), 1.

2) H. Nomura and K. Mori: Trans. Iron Steel Inst. Jpn., 13 (1973), 265.

3) H. Nomura and K. Mori: Trans. Iron Steel Inst. Jpn., 13 (1973), 325.

4) D. N. Ghosh: Ironmaking Steelmaking, 2 (1975), 36.

5) D. N. Ghosh: Ironmaking Steelmaking, 2 (1975), 45.

6) D. R. Sain and G. R. Belton: Metall. Trnas. B, 7 (1976), 235.

7) D. R. Sain and G. R. Belton: Metall. Trnas. B, 9 (1978), 403.

8) H. G. Lee and Y. K. Rao: Metall. Trnas. B, 13 (1982), 403.

9) H. G. Lee and Y. K. Rao: Metall. Trans, B, 13 (1982), 411. 
ISIJ International, Vol. 33 (1993), No. 8

10) K. Harashima, S. Mizoguchi and H. Kajioka: Tetsu-to-Hagané, 74 (1988), 409.

11) S. Matoba and T. Fuwa: Tetsu-to-Hagane, 53 (1967), 766.

12) R. Sakagami: Tetsu-to-Hagané, 52 (1966), 1738.

13) S. Taniguchi, A. Kikuchi and S. Maeda: Tetsu-to-Hagané, 62 (1976), 191.

14) K. Kadoguchi, M. Sano and K. Mori: Tetsu-to-Hagané, 71 (1985),
70.

15) T. Emi and R. D. Pehlke: Metall. Trans. B, 6 (1975), 95.

16) S. Banya and J. D. Shim Tetsu-to-Hagané, 66 (1980), 1631.

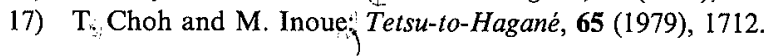

(Originally published in Tetsu-to-Hagané, 77 (1991), 377, in Japanese) 